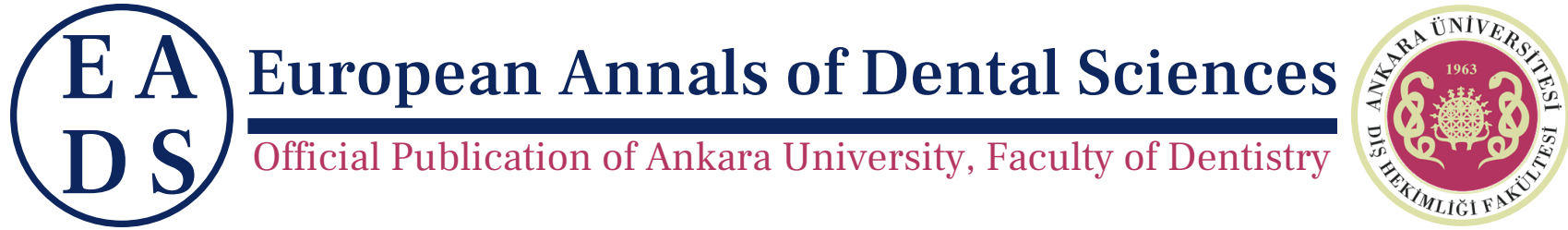

EADS, 2021, 48 (3), 119-123

\title{
Full-mouth reconstruction with Implant and Tooth-supported Zirconia Restorations in a Digital Workflow
}

\author{
Ece İrem Oğuz $\odot$ 1,* and Mehmet Ali Kılıçarslan $\odot 2$ \\ ${ }^{1}$ DDS, Department of Prosthodontics, Ankara University Faculty of Dentistry, Ankara, Turkey. and ${ }^{2}$ DDS, \\ $\mathrm{PhD}$, Department of Prosthodontics, Ankara University Faculty of Dentistry, Ankara, Turkey. \\ *Corresponding Author; eikiyan@ankara.edu.tr
}

\begin{abstract}
Zirconia has become a popular restorative material regarding the mechanical and biocompatibility advantages. Monolithic and translucent forms of zirconia advanced the aesthetics of this material, making it the material of choice for both tooth- and implant- supported restorations. Also, digital fabrication of zirconia not only enables accurate restorations but also provides time efficiency. The present case report demonstrates the rehabilitation of a patient who has generalized tooth wear with implant- and tooth-supported monolithic zirconia restorations with buccal veneers in a newly established occlusal vertical dimension. The treatment process was completed in a digital workflow as the impressions were taken with a powder-free intraoral scanner and the digital data were send to the dental laboratory to fabricate the restorations. Monolithic zirconia restorations with buccal feldspathic veneers were completed without any adjustments in only two appointments. The patient was satisfied and the restorations have been in service for two years.
\end{abstract}

Key words: CAD/CAM; implant; monolithic; zirconia.

\section{Introduction}

Developments in computer-aided design/computer-aided manufacturing (CAD/CAM) technologies gave rise to advances in related fields of prosthodontic applications from treatment concepts to material choices. CAD/CAM treatments, which started with glass-ceramic single-tooth restorations, can now be applied to full-arch reconstructions for both implant and tooth-supported restorations with a wide range of material choices available. ${ }^{1,2}$ Among these materials, zirconia ceramics stand forward with advantageous properties such as good biocompatibility, high strength, excellent load-bearing capacity, and recently, increased aesthetic characteristics with translucent and monolithic forms. ${ }^{2,3}$ Zirconia restorations are manufactured either monolithic, partially veneered or fully veneered with feldspathic porcelain. ${ }^{1}$ When zirconia was used as a framework and fully veneered, the most frequently encountered complication was a fracture in the veneering ceramic, so-called chipping. ${ }^{3}$ To avoid such problems, the use of translucent zirconia in anatomic contour as monolithic restoration was proposed. To enhance the aesthetics of the restoration, a cut-back technique can be used which is applied on the buccal surface, leaving functional occlusal contacts as zirconia. ${ }^{4}$ The buccal facing is then veneered with feldspathic porcelain. 5 The risk of chipping is reduced with this type of zirconia restoration since porcelain to zirconia junction is protected from direct occlusal function. 4

Monolithic zirconia is introduced for the fabrication of implant-supported reconstructions as well as tooth-supported restorations. ${ }^{6}$ The use of zirconia as a restorative material for implant-supported prosthesis is highly referred in the past decade. 7,8 Besides aesthetic and mechanical advantages, zirconia was reported to demonstrate favorable biological periodontal/peri-implant parameters thanks to its good biological properties. ${ }^{6}$ Furthermore, the fact that zirconia is a digitally producible material offers benefits for both clinical practice and laboratory stages of the fabrication process for implant-supported prosthesis. ${ }^{8}$

This case report represents digital workflow for a fullmouth rehabilitation of tooth- and implant-supported monolithic zirconia restorations with buccal veneers. 


\section{Case Report}

A 57-year-old male presented to Ankara University Faculty of Dentistry with decayed and lost teeth (Figure $1 \mathrm{~A}$ ). Decayed \#13 and \#22 received endodontic treatment in the Endodontics Clinic and 4 implants (NucleOSS, Şanlılar Ltd. ŞTi, İzmir, Turkey) were inserted to restore lost teeth (Figure 1B). Following the osseointegration period, the patient referred to Prosthodontics Clinic to receive implant-supported fixed restorations.

In the clinical examination, severely worn teeth because of bruxism attracted attention (Figure 2). The patient did not report any pain related to temporomandibular junction (TMJ). Also, TMJ examination did not reveal any disorders. Fullmouth rehabilitation of the dentition with monolithic zirconia restorations was planned except for \#27, \#45, \#46, and \#47 as those teeth did not affect from the wear. As the patient agreed with the treatment, the Niswonger method was used to determine the magnitude of OVD loss because of tooth wear. ${ }^{9}$ The loss in OVD was assessed as $3 \mathrm{~mm}$ and the restorations were planned according to this newly established OVD. To achieve this, condensation silicone (Zetaplus; Zhermach Dental, Badia Polesine, Italy) putty material was placed on the occlusal surfaces of molar teeth prior to preparations and two molds that guide the registered OVD were obtained. First, preparations on the right maxillary and mandibular teeth were performed and the occlusal reductions were checked according to the left putty mold to evaluate the restorative space. A new putty mold was
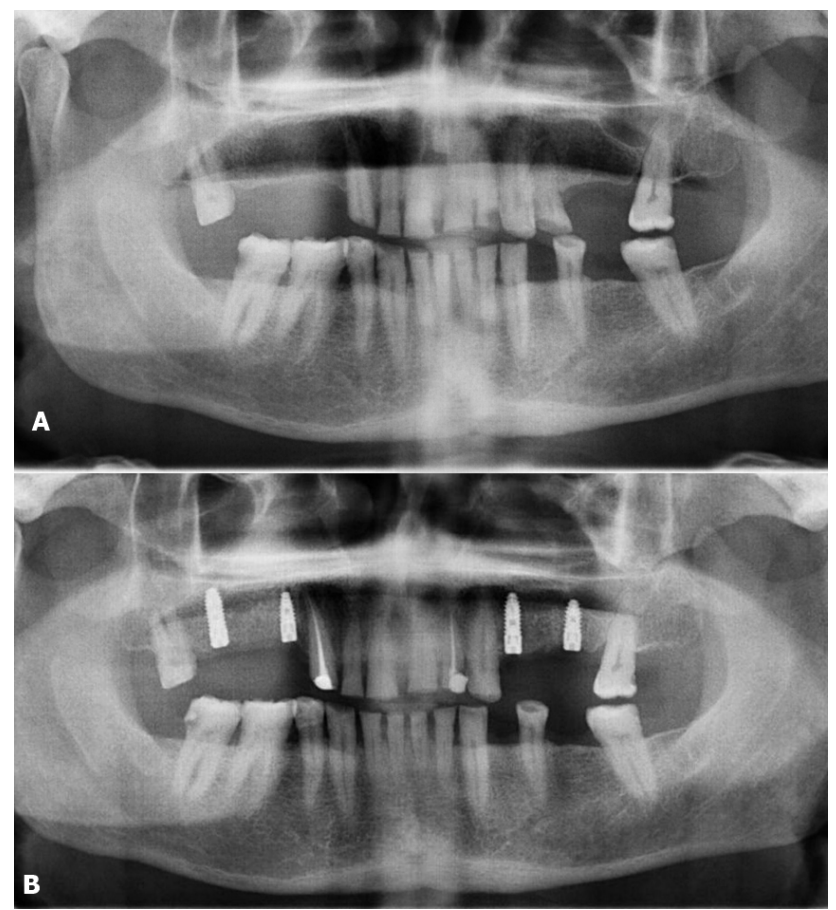

Figure 1. Panoramic radiograph of the patient A: Before any treatment B: When he referred to the Clinic of Prosthodontics

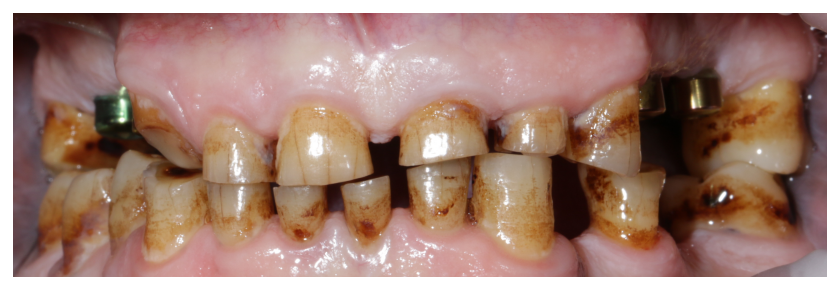

Figure 2. Intraoral photographs of the patient before prosthodontic treatment

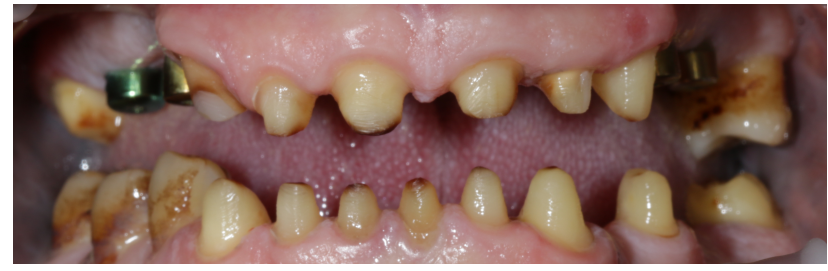

Figure 3. Intraoral photographs of tooth preparations

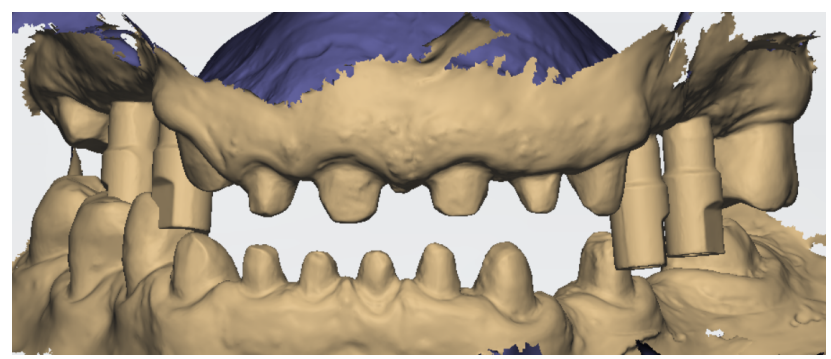

Figure 4. Digital impressions of prepared teeth and scan bodies placed on implants

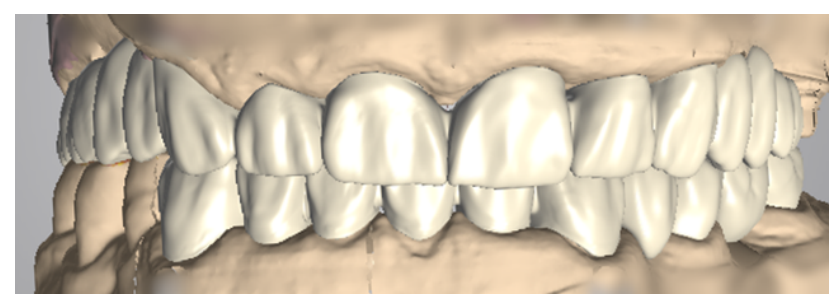

Figure 5. Full-contour design of the monolithic zirconia restorations

made on the prepared teeth. Then, left maxillary and mandibular teeth were prepared and a new putty mold was obtained based on the right putty mold. Therefore, the OVD determined based on the Niswonger method at the beginning of the treatment was reflected on the prepared teeth. The molds obtained on the preparations were preserved and referred as definitive occlusal molds (DOM) while taking the digital impressions and performing rehearsals.

Following tooth-preparations (Figure 3), healing caps on the implants were replaced with scan bodies and digital impressions of the maxillary and mandibular jaws were performed with a powder-free intraoral scanner (Trios 4; 3 shape, Copenhagen, Denmark) (Figure 4). Occlusal digital records were obtained by scanning the molar teeth at one side while placing the DOM on the other side. Then, the digital dataset was exported in standard tessellation language (STL) files and imported into the software (Exocad; exocad GmbH, Darmstadt, Germany) to design the restorations. First, all tooth- and implantsupported restorations were designed in full-contour (Figure 5). Implant-supported monolithic restorations were designed as screw-retained on prefabricated titanium (Ti) bases. Then, facial reductions were applied, maintaining the occlusal surfaces in zirconia to protect functional contacts. The designed restorations were milled by using a monolithic translucent partially-sintered zirconium-oxide ceramic disc (inCoris TZI C disc 16, A2; Sirona Dental Systems, Bensheim, Germany). After the milling of the restorations, sintering firing was completed according to the manufacturers' instructions in a ceramic furnace (inFire HTC speed; Dentsply Sirona). Monolithic zirconia implant-supported restorations were cemented on the Tibases (NucleOSS) with a self-adhesive resin luting cement (RelyX Unicem 2; 3M ESPE, St. Paul, MN, USA). 


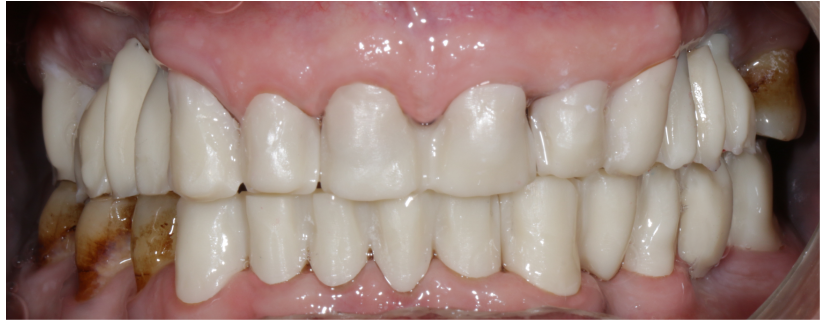

Figure 6. Monolithic zirconia restorations with buccal veneers

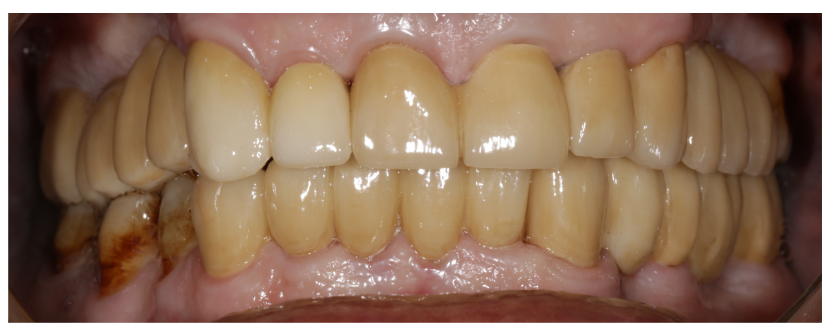

Figure 7. Definitive restorations cemented on prepared teeth.

The restorations were rehearsed intraorally to approve the occlusion and marginal fit (Figure 6). The occlusion was checked according to the predetermined OVD by placing the restorations on one side and placing the DOM on the other side. However, the patient considered the restorations as too white and requested natural, stained, and yellow-colored teeth that look alike his older teeth and his present molar teeth. The zirconia restorations were returned to the dental laboratory and the patients' request was forwarded to the dental technician. Conventional veneering porcelain (Vita VM 9, A3; Vita Zahnfabric, Bad Säckingen, Germany) was applied on the buccal veneers, then characterized, and glazed (Vita Akzent Plus; Vita Zahnfabric) (Programat P510; Ivoclar Vivadent, Schaan, Liechtenstein). On the second appointment following the digital impressions, the definitive restorations were approved by the patient and cemented with polycarboxylate cement (Adhesor Carbofine; Pentron, Spofa Dental, Jičín, Czech Republic). Implantsupported restorations were tightened to a torque of $25 \mathrm{Ncm}$ with a calibrated torque wrench (NucleOSS). The screw access holes on the implant-supported zirconia restorations were sealed with a composite resin (Filtek Z350 XT, 3M ESPE). The patient was pleased with the final results (Figure 7). Considering that the patient had severely worn dentition due to bruxism, a vacuum-formed soft night-guard (Duran; Scheu-Dental Gmbh, Iserlohn, Germany) was delivered to the patient immediately after the cementations to prevent the fracture. During the follow-up sessions at 6th month, 1st, and 2nd year after the delivery of the restorations, the patient did not reported any discomfort or symptoms related to TMD. The prostheses have been in place for over 2 years and no complications have occurred to date.

\section{Discussion}

The clinical long-term success of zirconia restorations is well proven; however, chipping was considered as a major complication for veneering porcelain. ${ }^{2,3}$ In this case report, this problem was avoided with buccal facings on full-contour monolithic restoration, maintaining high-load bearing areas on the occlusal surfaces as zirconia. Besides the advantages of predictability, high fracture strength, and good biocompatibility, zirconia as a restorative material enable enhanced adaptation of the restoration when manufactured with a digital process. ${ }^{10}$
Accurate marginal adaptation is of importance to prevent decementation, secondary caries, periodontal disease, and consequently to provide long-term success of the restoration. ${ }^{11,12}$ Sintering firing is required to achieve fully sintered zirconia restoration after the milling of partially-sintered zirconia. ${ }^{11}$ This process causes a linear sintering shrinkage by 15 to $30 \% .{ }^{13}$ Although improper marginal fit may be encountered due to this shrinkage, a recent study reported marginal adaptation for digitally fabricated full-arch zirconia restorations as satisfactorily precise. ${ }^{11}$ Zirconia restorations produced by CAD-CAM milling showed better marginal adaptation compared to other zirconia fabrication techniques. ${ }^{14}$ The high precision of fit is an essential feature for implant-supported restorations as well as tooth-supported ones to hinder screw loosening of implant reconstructions. ${ }^{6}$ In this case report, margins of CAD/CAM fabricated zirconia restorations were observed to be well-adapted.

Zirconia is a polymorphic metastable material that exists in three phases as monolithic, cubic, and tetragonal. ${ }^{15}$ Sintered zirconia restorations are present in the tetragonal phase at room temperature. ${ }^{16}$ However, tetragonal zirconia crystals may transform into monoclinic phase under stress such as occlusal adjusting and polishing. ${ }^{17,18}$ This phase transformation degrade mechanical properties of zirconia and compromises the predictability and longevity of the restoration. ${ }^{15,17}$ Unlike zirconia used as a substructure and covered by veneering glassceramic, full-contour or, as in this case, partial contour monolithic zirconia restorations are directly in contact with the opposing dentition and masticatory functions are performed on the zirconia surface. ${ }^{19}$ Because of the phase transformation that may occur during occlusal adjustments, monolithic zirconia restorations should be fabricated in their final forms. In the present case, the functionality of the occlusion was ensured on the zirconia restorations with the aid of the digital design software. No occlusal adjustment on the occlusal surfaces of the monolithic zirconia surfaces was performed in the rehearsals. Unlike other ceramics, polycrystalline ceramics do not contain silica and because of that, can not be acid-etched. ${ }^{20}$ Therefore, the main principle for the retention of zirconia restoration is micromechanical bonding which accommodates the basic considerations as the surface area of the preparation and the degree of convergence. ${ }^{21}$ Traditional cements such as glassionomer or polycarboxylate can be the cement of choice due to their ease of use and long-term clinical success on retentive preparations. ${ }^{21,22}$ Newly introduced zirconia primers in combination with resin cements may be beneficial when traditional retention/resistance form is lacking and higher bond strength is required. Polycarboxylate cement was chosen for the present case as the taper and length of the prepared teeth enabled micromechanical retention.

The patient in this case report had severely worn teeth before the treatment and an OVD loss was determined. The restorations were fabricated based on the newly established OVD determined by using the Niswonger method to restore OVD loss and to provide the restorative space for the prosthesis. The literature regarding OVD restoration defines two methods when increasing OVD: one- or two-step approach. ${ }^{23,24}$ The increase in OVD is tested by night-guards or provisional restorations with the two-step approach, while the definitive restorations in new OVD are directly cemented without a trial period when the one-step approach is adopted.24, 25 When an increase in OVD more than $5 \mathrm{~mm}$ inter-incisally is planned, it is recommended to test the new OVD by the two-step approach. ${ }^{25}$ In the present case, the one-step approach was employed as the increase in OVD was $3 \mathrm{~mm}$. The patient did not report any discomfort following the treatment and the restorations have been maintained for 2 years without any complications, confirming the validity of this approach. 


\section{Conclusion}

Monolithic zirconia fabricated with CAD/CAM technology is a viable treatment choice for full-arch tooth and implantsupported restorations. High accuracy, reduced clinical time, and minimal occlusal adjustments are the favorable advantages of digital systems. The present case report showed high success in function, patient satisfaction, and time-efficiency.

\section{Author Contributions}

Case planning and Methodology: EIO, MAK. Writing - Original Draft Preparation Creation and/or presentation of the published work: EIO. Writing - Review \& Editing: MAK. Both authors reviewed the results and approved the final version of the manuscript.

\section{Conflict of Interest}

Authors declare that they have no conflict of interest.

\section{Authors' ORCID(s)}

E.I.O. $\quad 0000-0001-6128-9723$

M.A.K. $0000-0002-8619-957 \mathrm{X}$

\section{References}

1. Papaspyridakos $\mathrm{P}$, Chochlidakis $\mathrm{K}$, Kang $\mathrm{K}$, Chen $\mathrm{YW}, \mathrm{Al}-$ ghfeli A, Kudara Y, et al. Digital Workflow for Implant Rehabilitation with Double Full-Arch Monolithic Zirconia Prostheses. J Prosthodont. 2020;29(6):460-465. doi:10.1111/jopr.13166.

2. Spitznagel FA, Boldt J, Gierthmuehlen PC. CAD/CAM Ceramic Restorative Materials for Natural Teeth. J Dent Res. 2018;97(10):1082-1091. doi:10.1177/0022034518779759.

3. Stawarczyk B, Frevert $K$, Ender A, Roos $M$, Sener B, Wimmer T. Comparison of four monolithic zirconia materials with conventional ones: Contrast ratio, grain size, four-point flexural strength and two-body wear. J Mech Behav Biomed Mater. 2016;59:128-138. doi:10.1016/j.jmbbm.2015.11.040.

4. Marchack BW, Sato S, Marchack CB, White SN. Complete and partial contour zirconia designs for crowns and fixed dental prostheses: a clinical report. J Prosthet Dent. 2011;106(3):145-152. doi:10.1016/s0022-3913(11)60112-1.

5. Diéguez-Pereira $M$, Chávarri-Prado $D$, Estrada-Martínez A, Pérez-Pevida E, Brizuela-Velasco A. Monolithic and Minimally Veneered Zirconia Complications as ImplantSupported Restorative Material: A Retrospective Clinical Study up to 5 Years. Biomed Res Int. 2020;2020:8821068. doi:10.1155/2020/8821068.

6. Worni A, Katsoulis J, Kolgeci L, Worni M, MericskeStern R. Monolithic zirconia reconstructions supported by teeth and implants: 1- to 3-year results of a case series. Quintessence Int. 2017;48(6):459-467. doi:10.3290/j.qi.a38138.

7. Abdulmajeed AA, Lim KG, Närhi TO, Cooper LF. Complete-arch implant-supported monolithic zirconia fixed dental prostheses: A systematic review. J Prosthet Dent. 2016;115(6):672-677.e1. doi:10.1016/j.prosdent.2015.08.025.

8. Sadowsky SJ. Has zirconia made a material difference in implant prosthodontics? A review. Dent Mater. 2020;36(1):1-8. doi:10.1016/j.dental.2019.08.100.
9. Sudhir N, Chittaranjan B, Kumar BA, Taruna M, Kumar MP, Reddy MR. Digital Cephalometric Tracings by PROCEPH V3 Software for Comparative Analyses of Vertical Dimension in Edentulous Patients. J Clin Diagn Res. 2015;9(5):Zc01-5. doi:10.7860/jcdr/2015/12034.5862.

10. Guichet DL. Digital Workflows in the Management of the Esthetically Discriminating Patient. Dent Clin North Am. 2019;63(2):331-344. doi:10.1016/j.cden.2018.11.011.

11. Juntavee N, Sirisathit I. Marginal accuracy of computeraided design- and computer-aided manufacturingfabricated full-arch zirconia restoration. Clin Cosmet Investig Dent. 2018;10:9-17. doi:10.2147/ccide.s154156.

12. Sailer I, Fehér A, Filser F, Gauckler LJ, Lüthy H, Hämmerle $\mathrm{CH}$. Five-year clinical results of zirconia frameworks for posterior fixed partial dentures. Int J Prosthodont. 2007;20(4):383-388.

13. Reich S, Wichmann M, Nkenke E, Proeschel P. Clinical fit of all-ceramic three-unit fixed partial dentures, generated with three different CAD/CAM systems. Eur J Oral Sci. 2005;113(2):174-179. doi:10.1111/j.16000722.2004.00197.x.

14. Papadiochou S, Pissiotis AL. Marginal adaptation and CAD-CAM technology: A systematic review of restorative material and fabrication techniques. J Prosthet Dent. 2018;119(4):545-551. doi:10.1016/j.prosdent.2017.07.001.

15. Caglar I, Ates SM, Yesil Duymus Z. The effect of various polishing systems on surface roughness and phase transformation of monolithic zirconia. J Adv Prosthodont. 2018;10(2):132-137. doi:10.4047/jap.2018.10.2.132.

16. Cakir-Omur T, Gozneli R, Ozkan Y. Effects of Silica Coating by Physical Vapor Deposition and Repeated Firing on the Low-Temperature Degradation and Flexural Strength of a Zirconia Ceramic. J Prosthodont. 2019;28(1):e186-e194. doi:10.1111/jopr.12618.

17. Karakoca S, Yilmaz H. Influence of surface treatments on surface roughness, phase transformation, and biaxial flexural strength of Y-TZP ceramics. J Biomed Mater Res B Appl Biomater. 2009;91(2):930-937. doi:10.1002/jbm.b.31477.

18. Mohammadi-Bassir M, Babasafari M, Rezvani MB, Jamshidian M. Effect of coarse grinding, overglazing, and 2 polishing systems on the flexural strength, surface roughness, and phase transformation of yttrium-stabilized tetragonal zirconia. J Prosthet Dent. 2017;118(5):658-665. doi:10.1016/j.prosdent.2016.12.019.

19. Huh YH, Park CJ, Cho LR. Evaluation of various polishing systems and the phase transformation of monolithic zirconia. J Prosthet Dent. 2016;116(3):440-449. doi:10.1016/j.prosdent.2016.01.021.

20. Dérand P, Dérand T. Bond strength of luting cements to zirconium oxide ceramics. Int J Prosthodont. 2000;13(2):131-135.

21. Griffin J J D. Combining monolithic zirconia crowns, digital impressioning, and regenerative cement for a predictable restorative alternative to PFM. Compend Contin Educ Dent. 2013;34(3):212-222.

22. Thompson JY, Stoner BR, Piascik JR, Smith R. Adhesion/cementation to zirconia and other non-silicate ceramics: where are we now? Dent Mater. 2011;27(1):71-82. doi:10.1016/j.dental.2010.10.022.

23. Abduo J, Lyons K. Clinical considerations for increasing occlusal vertical dimension: a review. Aust Dent J. 2012;57(1):2-10. doi:10.1111/j.1834-7819.2011.01640.x.

24. Oudkerk J, Eldafrawy $M$, Bekaert S, Grenade C, Vanheusden A, Mainjot A. The one-step no-prep approach for full-mouth rehabilitation of worn dentition using PICN CAD-CAM restorations: 2-yr results of 
a prospective clinical study. J Dent. 2020;92:103245. doi:10.1016/j.jdent.2019.103245.

25. Vailati F, Carciofo S. CAD/CAM monolithic restorations and full-mouth adhesive rehabilitation to restore a patient with a past history of bulimia: the modified three-step technique. Int J Esthet Dent. 2016;11(1):36-56. 